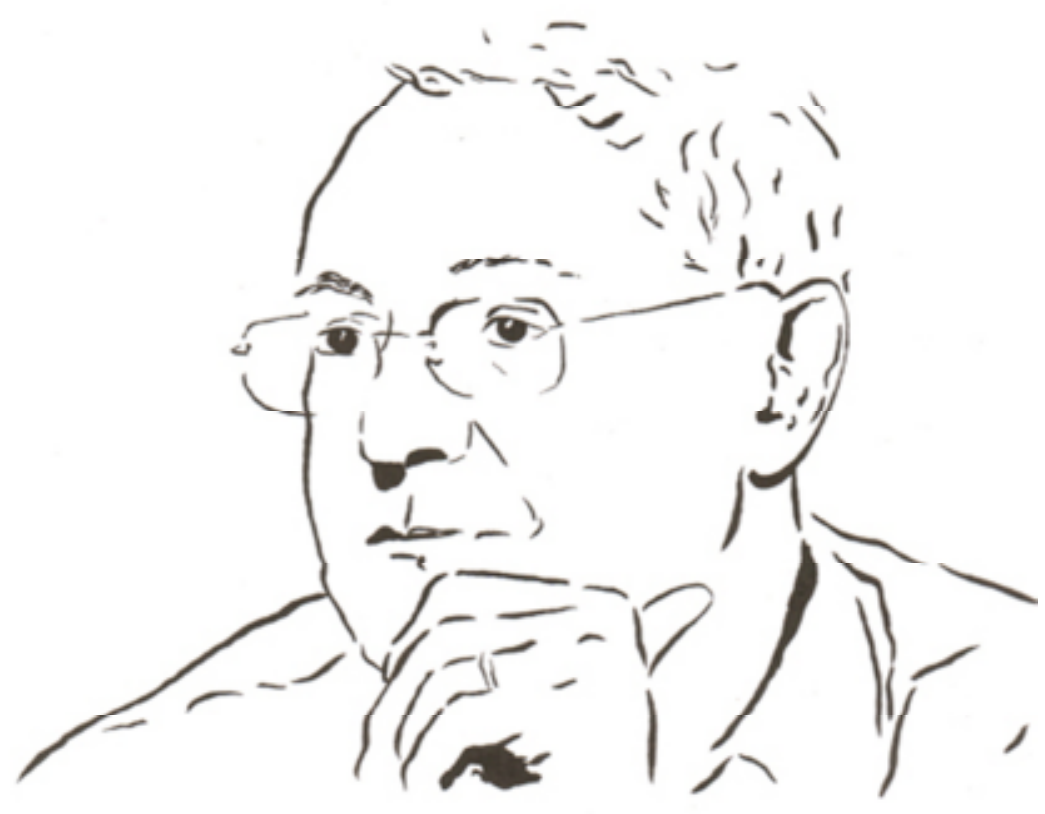

Mariana Parzewski

\title{
Memória e cibercultura \\ Entrevista com Pierre Lévy
}

\section{Por Lynnda Proulx e Maria Antonieta Pereira Tradução de Anderson Fabian Ferreira Higino}

Pierre Lévy é Titular da Cadeira de Pesquisa em Inteligência Coletiva na Universidade de Ottawa, Canadá. Membro da Sociedade Real do Canadá (Academia Canadense de Ciências e Humanidades). Autor de várias publicações sobre as relações entre cibercultura, memória, realidade virtual e interatividade. Os conceitos desenvolvidos por Lévy, especialmente as idéias de hipertexto e inteligência coletiva, fundamentam as ações de formação de leitores/educadores do Programa A tela e o texto.

Lynnda Proulx é Mestre em Literatura. Doutoranda em Educação (Universidade de Ottawa, Canadá). Professora de Língua Francesa (La Cité Collégiale, ottawa). Áreas de interesse: identidade e coletividade, diversidade cultural, motivação de aprendizagem, francofonia.

Maria Antonieta Pereira é Coordenadora Geral do Programa A tela e o texto. 
Anderson Fabian Ferreira Higino é bacharel em Física e especialista em Ensino de Física (UFMG), mestre em Educação Tecnológica e professor dos cursos de Engenharia e Tecnologia (CEFET-MG). Doutorando em Ciência da Informação (ECI/UFMG), conta com apoio institucional do CEFET-MG e bolsa PIQDTEC CAPES/CEFET-MG em sua pesquisa sobre transdisciplinaridade. No Programa A tela e o texto(FALE/UFMG), é coordenador voluntário do Fórum de Ensino de Leitura.

\section{Lynnda Proulx/Maria Antonieta - Para você, qual é a importância da tradição e da memória na cibercultura?}

Pierre Lévy - Talvez você fique um pouco desapontada, pois eu não tenho nada realmente novo a dizer. De todo modo, no tocante a essa questão... Bem, o ciberespaço é fundamentalmente uma tecnologia da memória, correto? Ou seja, as coisas são registradas digitalmente, em vez de serem impressas - digamos - ou gravadas em fitas magnéticas, e ficam acessiveis online. Desse modo, para mim, a grande novidade é que - concretamente, é o que está para acontecer - toda a memória da humanidade está em vias de ser digitalizada e disponibilizada online. E isso é completamente novo, porque em geral havia a memória de uma comunidade. Ou seja, havia memórias fragmentadas, umas ao lado das outras, elas não estavam reunidas em conjunto. Agora é como se nós tivéssemos uma única biblioteca reunindo todas as bibliotecas, todos os centros de documentação, todos os jornais etc. - tudo reunido exatamente no mesmo espaço e automaticamente manipulável por meio de programas. Essa é uma situação para a qual não temos referências no passado cultural: não há instituições ou mesmo conceitos que se refiram a isso. Do meu ponto de vista, vamos aprender a domesticar essa situação progressivamente, através de muitas gerações provavelmente. Quanto à importância da tradição e da memória na cibercultura, está claro, para mim, que a cibercultura é uma tecnologia da memória. Pode ser a memória de curta duração, como a que é acumulada por um grupo em interação. Mas pode ser também a memória de longa duração, como a memória das gerações passadas que nos foi legada. E essa pode ser uma ocasião extraordinária para nos reapropriarmos dessa memória. É isso. Como temos pouco tempo, não darei uma resposta mais longa. Mas digamos que, para mim, não há qualquer contradição entre a cibercultura e a memória: é exatamente o contrário.

Como você relaciona as árvores do conhecimento com os princípios do hipertexto que dialogam com o conceito de rizoma de Deleuze/Guattari? Elas teriam uma estrutura arborescente e ao mesmo tempo rizomática? 
o que aconteceu foi que Guattari viu as árvores do conhecimento - eu fiz muitas apresentações em sua presença - e as pessoas diziam "Mas como...? ". Enfim, acusaram-me de não ter respeitado a ortodoxia, porque as chamei de "árvores" sendo que, no texto de Deleuze e Guattari, as árvores estão condenadas ao benefício do rizoma. E Guattari disse a essas pessoas: "São árvores se vocês quiserem. Mas são árvores que são rizomas, porque, de início, há muitas árvores possíveis. E elas se comunicam como por um tecido, pois há coletivos humanos que as fazem crescer e que se comunicam por tecidos como o rizoma, de maneira horizontal." De todo modo, imaginei as árvores do conhecimento com alguns colegas em 1992, quer dizer, antes da web... Logo, isso é algo muito antigo... São sistemas de visualização dos conjuntos de conhecimentos e de competências pertencentes a grupos de pessoas, de maneira que elas pudessem se situar a si próprias no conjunto dos conhecimentos do grupo, além de encontrar os conhecimentos dos outros, em função dos seus próprios ou daqueles dos quais precisam para realizar projetos, para trocar saberes etc. Repare que não se trata de falar em gestão do conhecimento. Quer dizer, não se trata apenas de aumentar a produtividade das empresas, mas também de dinamizar os coletivos humanos em geral. Tenta-se valorizar ao máximo todos os conhecimentos e todas as competências, tornando-os conhecidos, fazendo-os servir para algo etc. É, portanto, nessa ótica que eu desenvolvi esse programa de computador. Mas, hoje, eu estou envolvido com outros projetos de pesquisa que trabalham um pouco na mesma direção, ou bastante na mesma direção, mas que vão muito mais longe e nos quais a dimensão do rizoma é ainda mais evidente. Eu me pergunto se você já viu as coisas que vou Ihe mostrar agora (Lévy abre uma tela de computador que mostra uma árvore de conhecimento). Bom, isso é uma árvore, e cada nó aqui representa uma significação. Eu gero automaticamente essas árvores de significação e gero cadalink entre, digamos, uma folha (ou um elemento da árvore) e a folha seguinte; ou, digamos, a geração seguinte - trata-se de uma função semântica particular. Assim, há muitas funções semânticas diferentes que interligam todos esses nós e, além disso, o mesmo nó poderia estar conectado a outras funções que viriam de outras árvores. Então, isso cria uma rede na qual não há uma árvore organizadora, mas uma multidão de árvores organizadoras que se entrecruzam. Bom, trata-se de árvores porque é mais prático montá-las, no contexto da informática, mas, ao final, resultam em verdadeiros rizomas. $E$ a idéia é criar, automaticamente, links hipertextuais como estes, porque hoje muitos são criados à mão, certamente. Desse modo, tem-se um conjunto de nós semânticos para o qual se podem criar links hipertextuais automaticamente e que pode servir para indexar (1) os documentos que existem naweb. Isso permite navegar no interior da memória justamente em função das relações semânticas. Bom, hoje ainda não temos isso. Por 
exemplo, no Google, fazemos pesquisas com seqüências de caracteres: quer dizer, há uma letra que segue outra letra que segue outra letra... Não é possível fazer pesquisas sobre o sentido, sobre o conceito. E é isso que eu tento fazer. Para mim, as árvores do conhecimento existem há muito tempo - de 1992 a 2008 são 16 anos - e eu não trabalho mais com isso. Agora, faço algo ainda mais rizomático do que as árvores do conhecimento.

Há tempos, você mostrou que a humanidade construiu quatro espaços de significação - a Terra, o Território, o Espaço das Mercadorias e o Espaço do Saber. Os movimentos ecológicos poderiam ser considerados uma forma de reunir esses quatro espaços?

Bem, digamos que o movimento ecológico se ocupa mais da Terra, de fato. É preciso ocupar-se (risos), pois isso é necessário. Eu diria que, no movimento ecológico, há uma conexão entre a Terra e o Espaço do Saber, por ele estar muito ligado ao conhecimento científico. As ecologias se apóiam fortemente nas observações científicas, nos modelos científicos etc.

\section{Lynnda Proulx - Em termos da economia, do consumo?}

É isso. Mas esse é um modo de agir, afinal. Porque há diferentes modos de agir - por exemplo, há o consumo e o investimento responsáveis. Já o Território congrega as entidades políticas clássicas: como se vota etc. Mas eu diria que também é algo menos direto: é um modo de agir, é o objetivo que se quer alcançar por meio dessas ações, por meio dos diferentes espaços. No caso da ecologia, certamente, a Terra. Ou melhor, a biosfera.

Em sua proposta de inteligência coletiva, é fundamental a discussão de uma nova ética baseada na reciprocidade e na inclusão. Para além da família e da escola, quais seriam os espaços de aprendizagem nessa nova realidade?

Bem, que as TICs sejam baseadas num mínimo de reciprocidade, isso me parece evidente. Não há nada de especial aí E a inclusão é o contrário da exclusão (risos). Bem, quando se fala de inteligência coletiva, não se vai começar por excluir, evidentemente. Se a inteligência é coletiva, é porque o outro é visto em termos do que ele pode trazer de diferente ou original, de pessoal ou especial à soma das experiências ou competências que já existem. Como cada um tem um percurso de vida e um conjunto de dons pessoais, o outro é sempre algo que vai servir para enriquecer a inteligência coletiva. Há sempre um potencial enriquecedor. Cada pessoa traz um potencial de enriquecimento da inteligência coletiva. 
- conhecimento do outro, pouco importa de onde ele venha, pouco importa sua educação, tudo o que ele faz tem um valor... Mas é possível medir esse valor?

Eventualmente, é possível medi-lo, mas nunca de modo absoluto. Ele é sempre relativo a uma situação, às necessidades... Bom, eu não sei se sou muito bom em Física Quântica, mas quando se está no deserto e todo mundo está com sede, vale mais que eu seja bom em saber onde está o oásis. É isso o que eu quero dizer. Assim, é possivel medir o valor, mas é sempre um valor circunstancial. Por isso, não se sabe nunca a priori se haverá circunstâncias que vão tornar o saber de alguém algo muito útil. Os espaços de aprendizagem dessa nova realidade estão por todo lado: na empresa, na cidade, na vida associativa.

\section{Você define o outro como "aquele que sabe o que eu não sei" e propõe substituir o cogito cartesiano pelo cogitamos comunitário. Nesse caso, você estaria valorizando o saber- fazer que seria uma forma mais avançada de conhecimento?}

Bom, digamos que na inteligência coletiva existe uma maneira de ver. Para mim, a inteligência humana é muito ligada à tradição. Tudo o que eu sei, tudo o que eu sei fazer é, em grande medida, aquilo que me ensinaram a fazer. Ou seja, não fui eu que inventei, isso me foi transmitido. Assim, existe um estado de coisas em torno de mim que me permite fazer de tudo - por exemplo, há computadores, telefones, lâmpadas etc. -, que amplia minha capacidade de ação e, ainda assim, não fui eu que inventei tudo isso. Há alguns livros que eu mesmo escrevi, mas a maioria dos livros não fui eu que escrevi. o que quero dizer é que nós estamos, o tempo todo, envolvidos numa rede extraordinária de saberes acumulados, incorporados nos objetos técnicos e sintetizados numa cultura, certo? Logo, a inteligência coletiva está aí, em volta de nós, na memória. Ela está também na troca, no diálogo, mas está muito maciçamente na memória. Nós agregamos algumas coisas. Mas é nada isso que podemos agregar pessoalmente, em relação ao que já estava aí quando chegamos. Isso é próprio do ser humano: estamos numa cultura e, por isso, não chegamos completamente nus e no meio de nada. Somos introduzidos na vida dentro de uma cultura.

\section{Nesse caso, você estaria valorizando o saber-fazer, que seria uma forma mais avançada de conhecimento?}

Bom, o saber-fazer é um conhecimento orientado para a prática, enquanto o conhecimento é abstrato e tem a grande vantagem de poder ser desvinculado de uma situação ou de um contexto particular. Digamos que, uma vez abstraído de uma situação particular, o conhecimento pode ser reutilizado noutra situação. Então, essa é a grande vantagem da abstração. Mas eu 
creio que existe uma dialética entre a abstração (conhecimento retirado da ação) e o saber-fazer(ação que se é capaz de efetuar numa dada situação, a partir do conhecimento). Então, digamos que há uma parte de abstração, a partir da prática, e uma parte de exercício bem dominado de uma ação, a partir de um conhecimento. É uma dialética: os dois são necessários.

Em toda a sua obra, você enumera vários fatores que contribuem para o desenvolvimento da inteligência coletiva e da democracia direta. Os grupos auto-organizados ou os grupos moleculares poderiam ser considerados a forma de organização típica desse processo? Esses grupos teriam uma organização hipertextual?

Isso depende dos grupos. Bem, uma organização burocrática federal em ottawa, por exemplo, não é necessariamente uma organização hipertextual. Pode ser muito pesada, muito burocrática, muito hierárquica etc. Mas essa é uma organização oficial. Há sempre uma organização oficiosa, na qual há relações transversais, as pessoas se conhecem etc. Há diferentes dimensões das organizações... As novas tecnologias de comunicação podem favorecer modos de organização mais flexíveis, mais transversais, mais hipertextuais - mas isso não é automático... Logo, é preciso se apoiar ao máximo nesses instrumentos, quando estão disponíveis, para dinamizar os grupos, os coletivos, as organizações.

\section{Maria Antonieta - Mas há um tipo de grupo que é auto- organizado e molecular...}

Bem, são duas noções diferentes, porque "auto-organizado" quer dizer que o grupo cria para si mesmo sua própria lei ou sua própria organização. "Molecular" é outra coisa. Se você puder ter um grupo "molar" que seja auto-organizado...

\section{Maria Antonieta - $\boldsymbol{E}$ se o grupo for molecular e auto-organizado,} ao mesmo tempo?

... é que molecular quer dizer, na verdade, que não há instituição que defina o pertencimento ao grupo, em termos de grandes categorias. Por exemplo, se eu digo os homens e as mulheres, isso são grupos molares. Ou se eu digo os pobres e os ricos... também são grupos molares. Mas se eu conecto singularidades ou pessoas, esses são grupos moleculares, porque se definem a partir de um pequeno nível de especificação e não de um grande nível. E se eu digo que há grupos moleculares auto-organizados... É possível hoje - creio eu - fazer surgir grupos moleculares auto-organizados mais facilmente graças às novas tecnologias, por causa de tudo que se relaciona às comunidades virtuais, às redes sociais etc. Porque as pessoas podem se conectar pelas características 
particulares que possuem. Mas se você analisa o Facebook ou - Myspace, não está lá a grande inteligência coletiva ultracriativa... Não é isso o que quero dizer. Não é porque as pessoas podem fazer coisas extraordinárias que elas as fazem... (risos). Para isso, é preciso um projeto, mobilização social etc. Não se trata de algo automático.

\section{Você aborda a construção de coletivos pensantes como a mais importante característica da sociedade contemporânea. Em termos educacionais, que relações haveria entre essa idéia e a prática da transdisciplinaridade?}

Digamos que a finalidade dos grupos é pensar em conjunto, pensar melhor em conjunto etc. É verdade que isso sempre existiu, mas é também verdade que isso se desenvolve cada vez mais. Por exemplo, a comunidade cientifica: em princípio, é sua razão de ser esse pensar em conjunto. Mas agora, cada vez mais, exige-se das pessoas que trabalhem em conjunto - nas empresas, nas administrações - que funcionem numa inteligência coletiva. Isso até chega a ser o objeto de toda uma corrente da gestão, o knowledge management. A idéia é que cada pessoa se considere contribuinte da memória coletiva e, ao mesmo tempo, possa buscar recursos na memória coletiva. Se há uma memória coletiva, cada um a alimenta e vai nela se alimentar. E assim se constrói uma inteligência coletiva. Logo, esse modo de pensar o grupo vai-se tornar o modo padrão na cultura do futuro. Mesmo que ainda não seja assim, é possível ver que nós caminhamos nessa direção... E que relações haveria entre essa idéia e a prática da transdisciplinaridade? Bem, uma disciplina tem uma tradição, tem uma memória, um conjunto de produções, de resultados, de publicações etc. Mas essa memória é separada da memória de outra disciplina. É uma memória fragmentada. Mas, se tentamos pensar em termos de inteligência coletiva, como desfragmentar a memória? E esse é o grande problema, na minha opinião. É a dificuldade de trabalhar na desfragmentação da memória. É por isso que eu tento imaginar um sistema de coordenadas semânticas que defina um espaço semântico quasi-infinito que seja capaz de envolver todas as diferentes memórias fragmentadas no mesmo espaço aberto e infinito. Esse sistema seria maior - infinitamente maior - que todas as pequenas memórias fragmentadas. Nele, as pequenas memórias fragmentadas poderiam se comunicar umas com as outras. o que eu tento é dar um suporte técnico a essa idéia. Tornar calculável o espaço semântico. Para que se possa utilizar uma biblioteca de modo correto, é melhor que haja o mesmo sistema de organização para todos os documentos da biblioteca: o mesmo sistema de indexação e catalogação. Mas esse sistema é muito grosseiro, em realidade. No interior mesmo do sistema de documentação da biblioteca, existem os fichários, os títulos, os autores, as editoras, as datas, as palavras-chave. Mas os sistemas de catalogação e de documentação são diferentes no 
Brasil, na França, no Canadá, nos Estados Unidos, na Índia. Além disso, estão em línguas diferentes. E ainda que estejam na mesma língua, as palavras não têm o mesmo sentido: elas variam, de acordo com cada disciplina, por exemplo. Logo, como é a primeira vez que nos encontramos numa situação na qual toda a memória da humanidade está reunida no mesmo "continente", é preciso ter um sistema de navegação, no interior dessa memória, que seja a medida da nova situação. E tudo o que temos, no momento, foi elaborado a partir de situações diferentes, de memórias fragmentadas. Então, é preciso ter: 1) um sistema universal; 2) um sistema infinito, no sentido de poder ser infinitamente mais e mais preciso, e no sentido de se poder diferenciar os conceitos sem limite; 3) e, finalmente, a capacidade de se fazer cálculos com esses conceitos. Isso não pode ser feito se os conceitos forem expressos em linguagem natural. (risos) Isso é engraçado...

\section{Lynnda Proulx - Sim, pelo menos para mim...}

Isso é porque, há 50 anos, nós não tínhamos computadores. Então, essa questão nem tinha sido formulada. Não havia ciberespaço, não havia Internet, nada disso. Bom, acho que respondi a todas as suas questões...

\section{Nota}

[1] V. figura das árvores de hiperlinks no verbete da Wikipédia sobre Pierre Lévy. Disponível em: "target blank". Acesso em: 18 nov.2008.(N.T.)

Ottawa, jun./2008. 